\title{
JOURNAL.RU
}

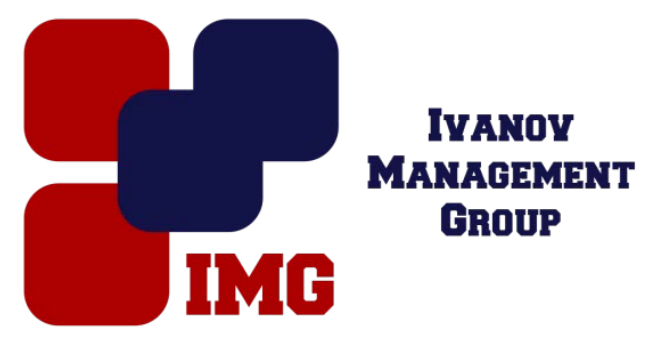

Молочков В.Я., Молочкова И.Д. Дальневосточный государственный технический рыбохозяйственный универ-ситет Владивосток, Россия

doi: 10.18411/lj-31-01-2017-3-07

idsp 000001:lj-31-01-2017-3-07

\section{Проблемный подход в создании методического и программного обеспечения подготовки электротехнического персонала судов}

\section{Аннотация}

В статье приводятся результаты создания программных средств подготовки электротехнического персонала судов с учетом проблемного подхода в обучении. Рассматриваются требования к таким программам, кратко описывается созданная по таким требованиям программа.

Ключевые слова: промысловые суда, обучение, проблемный подход, информационная среда обучения, тренажерные средства

\section{1. Влияние современной информационной среды на роль преподавателя в обучении}

Современная информационная среда, построенная на Internet co средствами мгновенного доступа к информации поисковыми системам, такими как Google, Yandex, резко снижает роль преподавателя как носителя информации и оставляет за ним, в основном, функции наставника. Это повышает требования к нему профессиональные и, как обосновано ниже, чисто человеческие.

Преподаватель-наставник должен быть в полном не формальном контакте c обучающим на самой начальной стадии обучения, вести его в информационной среде по выбранной области деятельности, ранжировать и оформлять информацию, помогать в освоении информации, создавать и использовать объективные методы контроля и поощрения. Естественно, он должен использовать современные средства коммуникации, Internet и не ограничивать время доступа обучающегося к себе как к наставнику.

Современный преподаватель должен: 
- знать все компетенции, которыми должен владеть учащийся после прохождения его курса;

- выработать на основе информации по своей дисциплине технические проблемы, характерные для деятельности данного вида специалиста;

- создать методические материалы для компьютерных видов обучения по этим компетенциям;

- продумать и методически разработать рекомендации для обучающихся по использованию материалов из Internet по его дисциплине;

- решить психологическую проблему внутренней мотивации обучающихся в познании его дисциплины, продумать свое поведение и подобрать материалы для повышении внутренней мотивации обучающихся.

\section{2. Основные положения проблемного подхода в обучении}

Следует отметить, что работа электротехнического персонала судов происходит в отрыве от помощи, характерной для береговых специалистов, требует быстрых решений, от которых зависит как живучесть судна, так и жизнь людей. Здесь как никогда «человеческий фактор» может определить результаты работы специалиста.

Анализ различных методов обучения показывает, что только проблемное изучение материала способно подготовить специалиста не с набором информации, а способного логически мыслить, находить решения в различных проблемных ситуациях, накапливать систематизированные знания.

Во многих работах педагогов показано, что педагогически правильно организованное обучение не может быть не проблемным. Принцип проблемности отражается в логике построение учебного процесса, в содержании изучаемого материала, в методах организации учебно-познавательной деятельности учащихся и управление ею, в структуре занятий и формах контроля преподавателя за процессом и результатом деятельности обучающихся.

При создании методики проблемного обучения и подготовке обучающих материалов могут использоваться все шесть дидактических способов

организации процесса проблемного обучения: монологическом, рассуждающем, диалогическом, эвристическом, исследовательском, методе программированных заданий. Из них для подготовки специалиста технического профиля наиболее эффективны два последних, которые легко могут быть оформлены для обучения с использованием лабораторной стендовой и тренажерной базы, а так же вычислительной техники.

$\begin{array}{cccccr}\text { Структура проблемного } & \text { занятия } & \text { применительно к } & \text { подготовке } \\ \text { электротехнического персонала } & \text { судов } & \text { включает обязательным этапом }\end{array}$


поисковую деятельность, которая представляет основную часть структуры проблемного урока:

- постановка проблемных технических ситуаций в обслуживании электрооборудования судов;

- выдвижение предположений и обоснования решений;

- опробование высказанных предположений по решению технической проблемы (в тренажерном варианте);

- проверка правильности решения проблемы с отсылкой к многоуровнему учебному электронному пособию в случае неправильного решения проблемы.

Следует отметить, что такая форма подготовки с обучением и самоконтролем, совместно с использованием вычислительной техники создает возможность управления и самоуправления самостоятельной учебной деятельностью обучающегося.

Психологи выделяют два класса мотивов: процессуально-содержательные (интринсивные, внутренние) и экстринсивные (внешние).

Внутренняя мотивация предполагает интерес и положительные эмоции от самого процесса познания.

Внешняя мотивация побуждается материальными благами, социальными факторами (статусом, престижем, властью, внешними требованиями).

Психологами отмечено (Д. Уайт), что внутренняя мотивация (процессуально-мотивированная) наиболее продуктивна и дает обучающемуся ощущение эффективности, а результатом его активности является рост компетентности.

Процессуально-содержательная мотивация (интринсивная мотивация) означает, что человек с радостью отдается делу, с удовольствием окунается в саму деятельность. Маловероятно, что у обучающихся может формироваться процессуальная мотивация в результате общения с преподавателем, который сам не процессуально-мотивирован т.е. не получает удовлетворения от содержания и процесса своей работы.

Обучение предусматривает наряду с передачей знаний также и передачу смыслов. Информацию можно передавать разнообразными способами - с помощью книг, лекций, баз данных в Internet и т.п. В отличие от этого передача смыслов в процессе обучения не возможна без внутренне мотивированного преподавателя, который демонстрирует не только знание, но и эмоциональное отношение к своему предмету. Внутренне-мотивированный специалист может быть более эффективен, чем внутренне не мотивированный носитель информации даже имеющий научные степени.

Ощущение учениками растущей собственной компетентности в будущей области профессиональной деятельности является существенным фактором развития процессуально-содержательной мотивации.

Характер способов оценки достижений обучающегося преподавателем ощутимо влияет на мотивацию учебы. Если в процессе обучения преобладают 
позитивные оценки, направленные на подчеркивание достижений обучающегося и излишне не концентрируется внимание на ошибках, то процессуальносодержательная мотивация усиливается. Если же преобладает внешний контроль и негативные оценки, которые свидетельствуют о неуспешности или некомпетентности обучающихся, то интринсивная мотивация снижается и освоение учебного материала тормозится.

Позитивное влияние на процессуально-содержательную мотивацию учеников и скорость усвоения материала относится свобода выбора учениками задач для домашней работы. Ощущение учениками постоянной строгой регламентации и контроля со стороны учителя значительно ослабляет процессуально-содержательную мотивацию. При таких условиях жесткого контроля и регламентации обучения обучающиеся воспринимать обучение как вынужденное, обусловленное внешне, внешне мотивированное. Это вызывает внутренний протест и снижает скорость и качество усвоения учебного материала.

\section{3 Проблемный подход в подготовке электротехнического персонала} судов

При подготовке электротехнического персонала судов наибольший эффект от применения проблемного подхода можно получить при разработке обучающих и тестовых программ для реализации компетенций по разделу специальных дисциплин.

На кафедре «Электрооборудование и автоматизация судов» Дальрыбвтуза проблемный подход применяется для выработки компетенций по обслуживанию судовой электроэнергетической системы при подготовке электротехнического персонала судов. К ним, в соответствии со стандартом последнего поколения для электромехаников судов специальности 16.05.07, относятся:

- эффективно эксплуатировать и выбирать оптимальные условия работы электроэнергетического оборудования;

- производить все необходимые оперативные переключения на ГРЩ;

- правильно оценивать ситуацию в энергосистеме по показаниям приборов на ГРЩ;

- находить и устранять неисправности в схемах энергосистемы.

Судовая автоматизированная электроэнергетическая система (САЭЭС) является самой сложной системой на судне, за которую отвечает электромеханик. Навыки работы с ней, доведенные до автоматизма, являются необходимым условием безаварийной работы.

Проведенный анализ компетенций позволил выделить основные функции при обслуживании САЭЭС, которые позволяют реализовать выработку вышеперечисленных компетенций.

Структура этих функций, охватывающая все возможные режимы работы САЭЭС, приведена на рисунке 1 


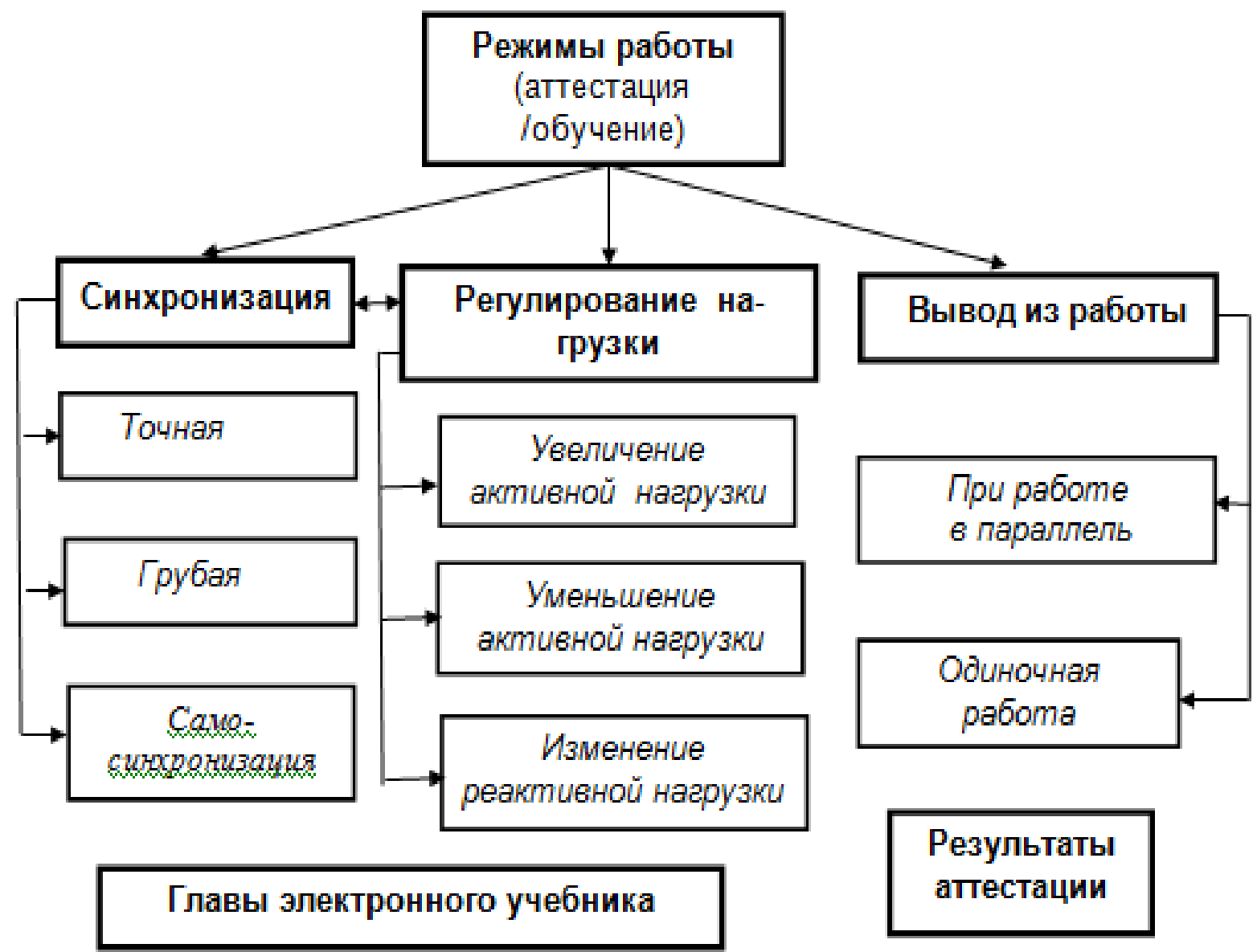

Рисунок 1. Структура функций, реализующая компетенциии по дисциплине САЭЭС

Тестовые программы, в основном, определят знания выпускника, навыки же следует развивать и определять на тренажере.

Комплексная проверка по программам тестирования и успешное прохождение тренажера является внешней мотивацией, но она позволит охватить весь спектр знаний и умений по специальным дисциплинам, исключить субъективизм преподавателя и посторонние влияния на результат.

При подготовке электромехаников, конечно, нельзя полагаться только на внутреннюю мотивацию обучающихся. Это связано как с сегодняшним контингентом обучающихся, так и преподавательским составом. Внутренняя мотивация и ее развитие должны быть маяком, к которому нужно стремиться. Если быть реалистами, то основной все-таки будет внешняя мотивация успешная сдача тестов и прохождение тренажера.

С учетом этих замечаний к компьютерному тренажеру были предъявлены следующие требования:

- доступность программы и возможность индивидуального пользования обучающимся;

- кроме тестового режима тренажера, наличие обучающего режима в виде электронного учебника, ссылки на разделы которого 
происходят при обучающем режиме и неправильных действиях с электростанцией;

- наличие всех режимов работы электростанции и синхронных генераторов, в том числе моделирование и аварийных;

- возможность моделирования нагрузок судовой электростанции в различных режимах работы судна.

Данная разработка учитывает требования, изложенные выше, и построена с применением программных средств для работы в среде Windows. Программа предназначена для выработки навыков эксплуатации электрических станций.

Программа выполнена на языке $\mathrm{C}++$ с использованием Microsoft foundation classes (MFC 4.2).

Задачи, решаемые программой:

1. Имитация работы судовой электрической станции в различных режимах.

2. Реакция на неправильные действия пользователя с выводом соответствующих сообщений об ошибках и последующим разъяснением последствий этих ошибок в реальной ситуации.

Предоставление пошаговых инструкций для обучения пользователя основным навыкам обслуживания судовой электростанции.

Программа «Судовая электростанция» позволяет воспроизводить следующие операции по обслуживанию судовой электростанции:

- ввод в работу, включение и выключение генераторов, изменение нагрузки;

- ввод генераторов в параллельную работу при различных режимах синхронизации;

- перераспределение активной и реактивной нагрузки между параллельно работающими генераторами;

- вывод из действия работающих генераторов.

Режимы работы программы позволяют производить обучение с привитием навыков работы на электростанции, производить проверку приобретенных навыков и знаний. В режиме обучения выдаются подсказки, позволяющие произвести ввод в действие и синхронизацию генераторов. 


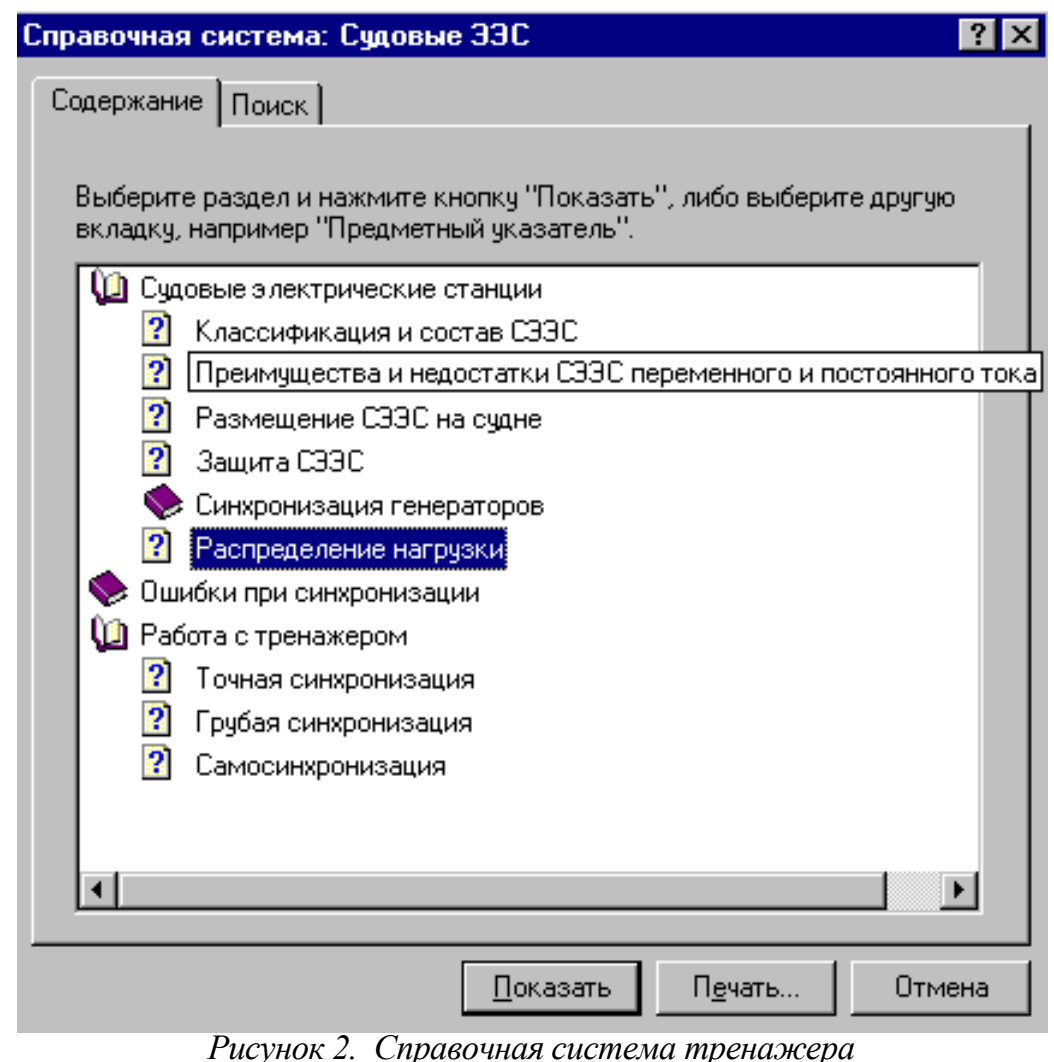

В обучающем режиме при совершении ошибочных действий пользователем (включение генератора в сеть при не выполненных условиях синхронизации, отключение при неснятой нагрузке и т.п.) выводится сообщение об ошибке и раздел справочной системы, в котором описаны последствия ошибки. Кроме того, в электронном учебнике можно подробно изучить все разделы по устройству и эксплуатации электростанции.

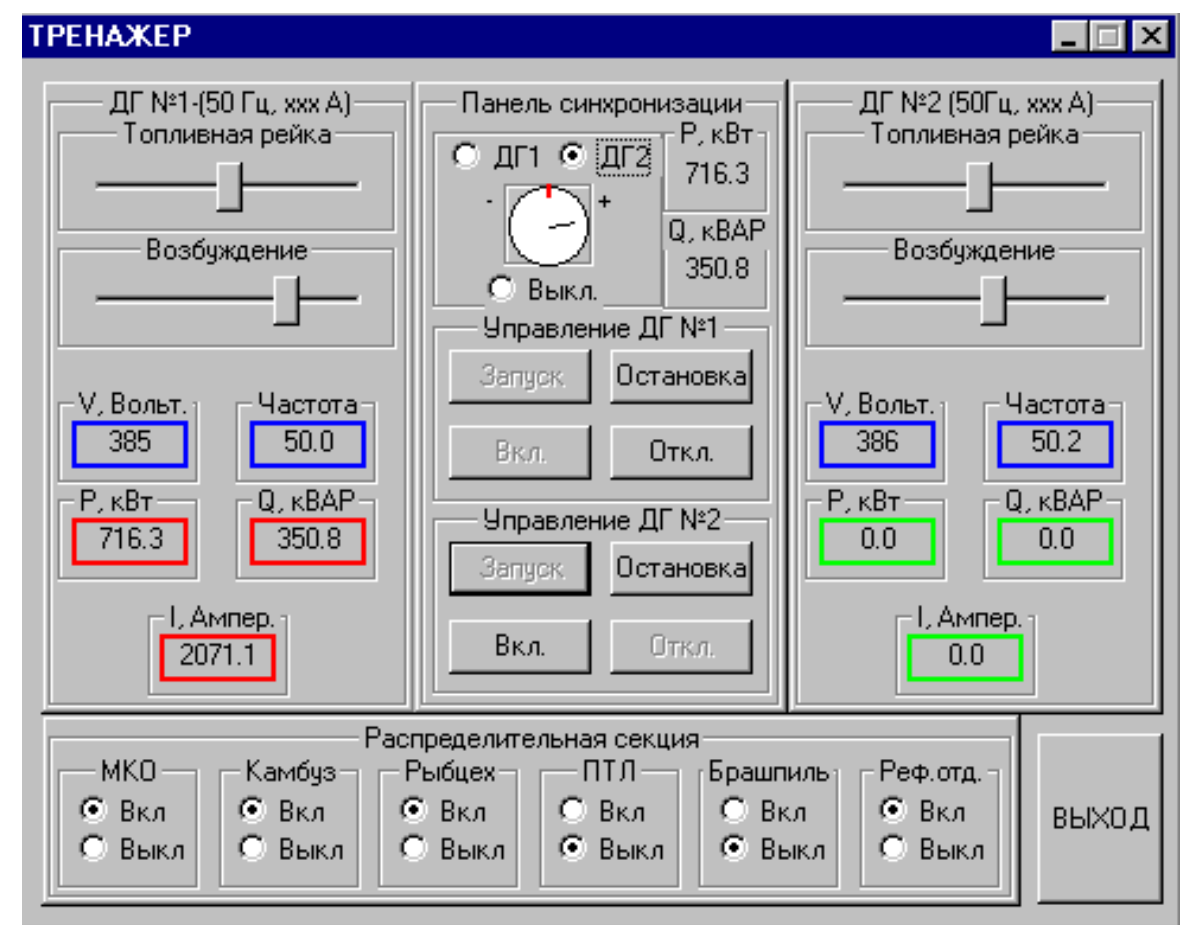

Рисунок 3. Рабочая панель программы тренажера 
Структура программы позволяет производить дальнейшее усовершенствование, в частности, реализацию автоматизированного приема зачета, ведение статистики ошибок студентов и т.д.

\section{Взаимодействие пользователя с программой.}

Программа выполнена с использованием стандартных элементов управления Windows, имитирующих органы управления генераторами электростанции. Внешний вид рабочей панели программы-тренажера в режиме точной синхронизации представлен на Рисунке 3

Экран программы выполнен в виде диалогового окна Windows, в котором расположены элементы управления двух генераторов, панели синхронизации и распределительной секции.

Пользователь при помощи элементов управления генераторами изменяет параметры их работы (частоту, напряжение) включает и выключает нагрузку и т.д. В соответствии с этими изменениями изменяется мощность, ток и другие параметры электростанции в целом.

Справочная система программы включает в себя описание режимов работы электрических станций, методов синхронизации, а также указания по работе с программой, назначение органов управления и описания ошибок, возникающих при работе.

Возможны следующие варианты выбора синхронизации генераторов станции:

a) Точная синхронизация.

б) Грубая синхронизация.

в) Самосинхронизация.

\section{Режим работы пользователя с программой:}

a) Работа.

В этом режиме пользователь может производить в произвольном порядке все возможные действия с электростанцией - ввод генератора в работу, включение и отключение нагрузки, включение генераторов на параллельную работу, перераспределение нагрузки между параллельно работающими генераторами, отключение генераторов. В случае ошибочных действий выводится соответствующее сообщение и предлагается соответствующий раздел справочной системы.

\section{б) Тренировка (обучение).}

Режим предназначен для ознакомления пользователя с необходимой последовательностью действий при работе с программой. Элементы управления становятся доступными по мере выполнения необходимых действий. В процессе работы выводятся сообщения, которые описывают порядок действий при вводе генератора в работу, подключении нагрузки и при включении генераторов на параллельную работу. После выполнения всех необходимых действий все элементы управления становятся доступными, и пользователь может совершать любые действия в произвольном порядке. В случае ошибочных действий 
выводится соответствующее сообщение и предлагается соответствующий раздел справочной системы.

Программа реализует стандартный механизм обработки сообщений Windows и MFC. Каждому элементу управления сопоставлена функцияобработчик, отвечающая за обработку сообщений, адресованных данному элементу управления (или группе элементов). При реализации переходных процессов используется таймер и функция обработки сообщений таймера.

В программе используются алгоритмы вычислений, позволяющие создать видимость работы электростанции в реальном масштабе времени.

\section{Литература}

1. Занюк С. Психология мотивации. К.: Эльга-Н; Ника-Центр, 2002.

2. Молочкова И.Д. Тренажерная подготовка. Мет. Пособие. Дальрыбвтуз. Владивосток. 2011. $-126 \mathrm{c}$.

3. Молочкова И.Д. Автоматизация судовой электростанции. Учебн. пособие. Дальрыбвтуз. Владивосток. 2006. -84 с.

4. Баранов А. П., Раимов М. М. Моделирование судового электрооборудования и средств автоматизации. СПб.: Элмор, 1997. -232 с. 